\title{
An Atypical presentation of Acute Aortic Dissection in the Emergency Department
}

\author{
Ankur Verma, Wasil Rasool Sheikh, Sanjay Jaiswal \\ Department of Emergency Medicine, Max Super Speciality Hospital, I.P.Extension, New Delhi.
}

\section{Corresponding Author: \\ Dr. Ankur Verma \\ Email: anksv25@gmail.com}

This is an Open Access article distributed under the terms of the Creative Commons Attribution License (creativecommons.org/ licenses/by/3.0).

Received Accepted

Published

February 23, 2017

April 24, 2017

May 10, 2017

\begin{abstract}
Background: Acute aortic dissection, an emergent vascular catastrophe, varies in its clinical presentation and embraces a high mortality rate if not recognized early. The symptoms of acute aortic dissection may vary. Most patients complain of an abrupt onset of severe pain in the chest, back, or abdomen. Other uncommon presentation may be shortness of breath, pain in the arms or legs, weakness, or loss of consciousness. Case Report: We present a 50 year old male who presented with complaints of sudden onset of shortness of breath, sweating and pain in the right leg 30 minutes before arrival. Patient was diagnosed as having acute aortic dissection (Stanford Type A) with cardiac tamponade. Patient underwent a successful Bentall's procedure. Conclusion: Acute aortic dissection is uncommon but still poses a clinical challenge as patients can deteriorate very quickly. Patients may present with varied symptoms and it is imperative for an emergency physician to have high index of suspicion to diagnose these patients as soon as possible so that appropriate care can be administered.
\end{abstract}

Keywords: Aortic Aneurysm, Cardiac Tamponade, Dyspnea, Pain, Sweating.

\section{Introduction}

Acute aortic dissection is a challenging clinical emergency diagnosis first described by Morgagni more than 200 years ago [1]. It is characterized by separation of the layers of the aortic wall by extraluminal blood that enters the aortic wall, almost invariably through a luminal tear [2]. Acute aortic dissection, an emergent vascular catastrophe, varies in its clinical presentation and embraces a high mortality rate if not recognized early [3]. The symptoms of acute aortic dissection may vary. Most patients complain of an abrupt onset of severe pain in the chest, back, or abdomen [4].

In a case series collected from January 1996 to December 1998, 73\% patients complained of chest pain (of note, pain was described mostly as sharp rather than tearing or ripping) [5]. Other uncommon presentation may be shortness of breath, pain in the arms or legs, weakness, or loss of consciousness. Acute aortic dissection may be uncommon, but complications occur often and early and the outcome is frequently fatal [6]. It is imperative for an emergency physician to have high index of suspicion to diagnose these patients as soon as possible so that appropriate care can be administered.

\section{Case Report}

A fifty year old man presented to the emergency department (ED) at 1645 hours with complaints of sudden onset of shortness of breath followed by profuse sweating and right leg pain and numbness since thirty minutes before arrival. He presented with a respiratory rate of $28 /$ minute, oxygen saturation of $96 \%$, pulse rate of $84 /$ minute, blood pressure of $130 / 80 \mathrm{mmHg}$, temperature of $98.4^{\circ} \mathrm{F}$ and random sugar of $203 \mathrm{mg} / \mathrm{dL}$. Patient was anxious, sweating profusely and had muffled heart sounds. Right femoral pulses were feeble with no 
radio-radial or radio-femoral delay. Rest of the systemic examination was unremarkable. Patient had no prior medical history but was a chronic smoker. Patient was given intravenous diclofenac, tramadol, ondansetron and crystalloids.

Electrocardiogram (ECG) was normal and patient underwent urgent bedside Trans-thoracic echocardiography (TTE) which revealed a dilated aortic root with flap in ascending aorta and arch with mild circumferential pericardial effusion [Fig.1,2]. He underwent elective rapid sequence intubation and was shifted for urgent $\mathrm{CT}$ aortogram which revealed acute aortic dissection (Standford Type A) with contained aortic rupture and pericardial effusion [Fig.3-5]. Urgent Cardiovascular and Thoracic Surgery (CTVS) consult was taken and patient shifted directly to the operation theater.

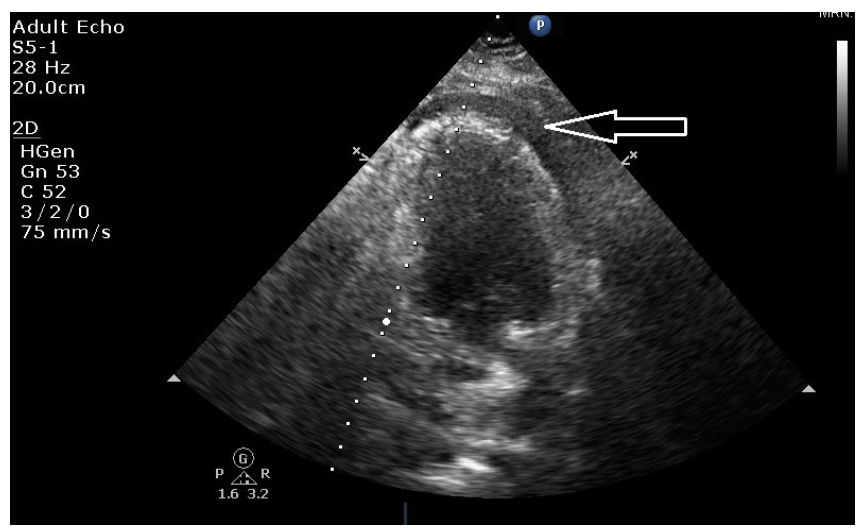

Fig.1: Echocardiography showing pericardial effusion.

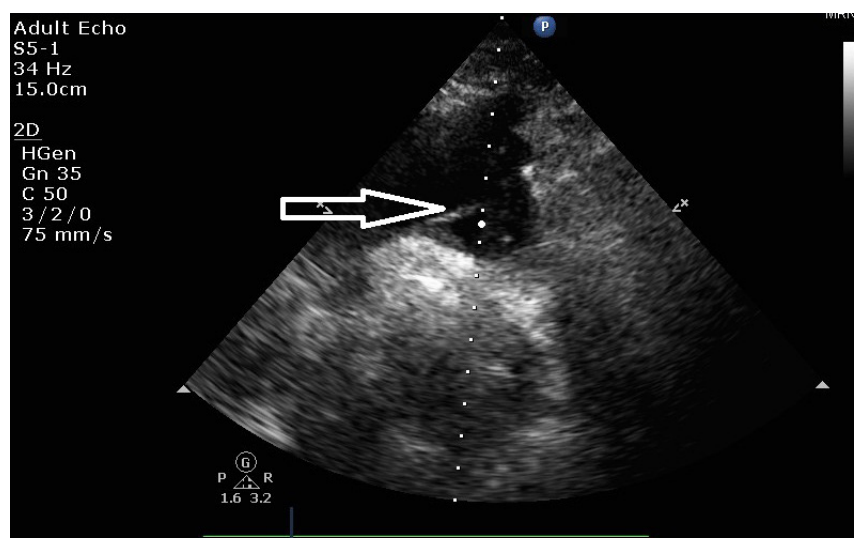

Fig.2: Echocardiography showing dilated aortic root with flap.

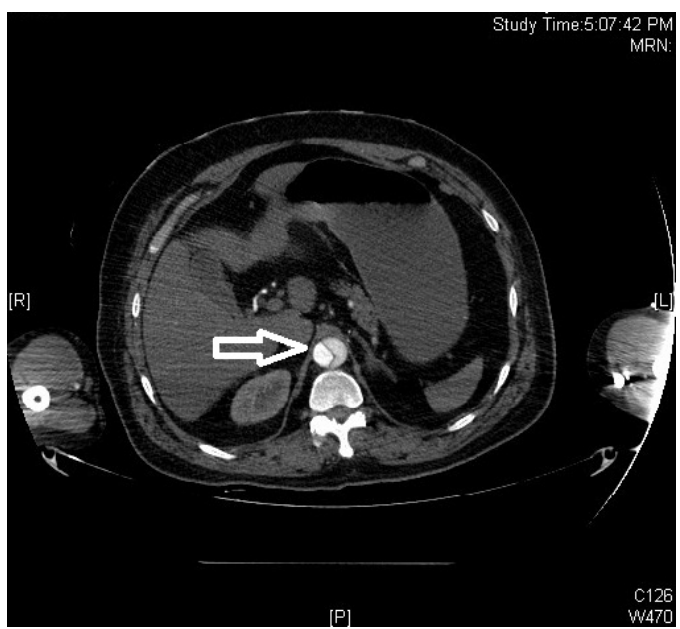

Fig.3: CT aortogram with dissection flap in descending aorta.

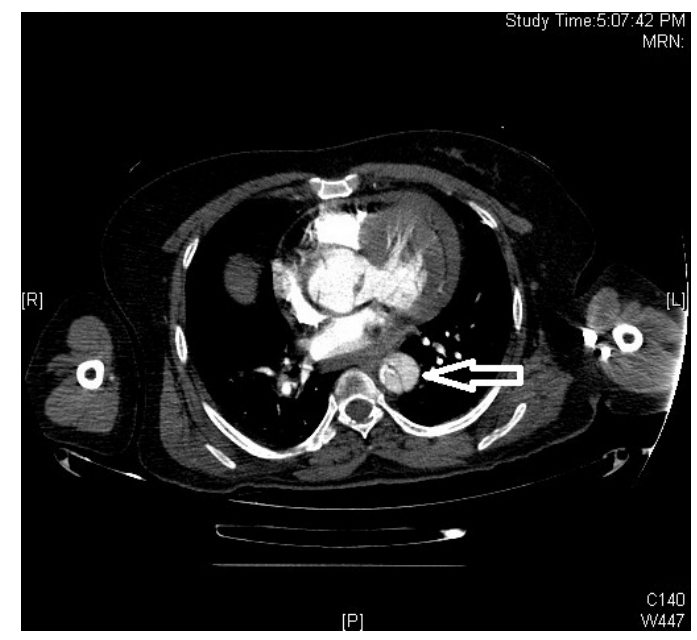

Fig.4: CT aortogram with dissection flap in aortic arch.

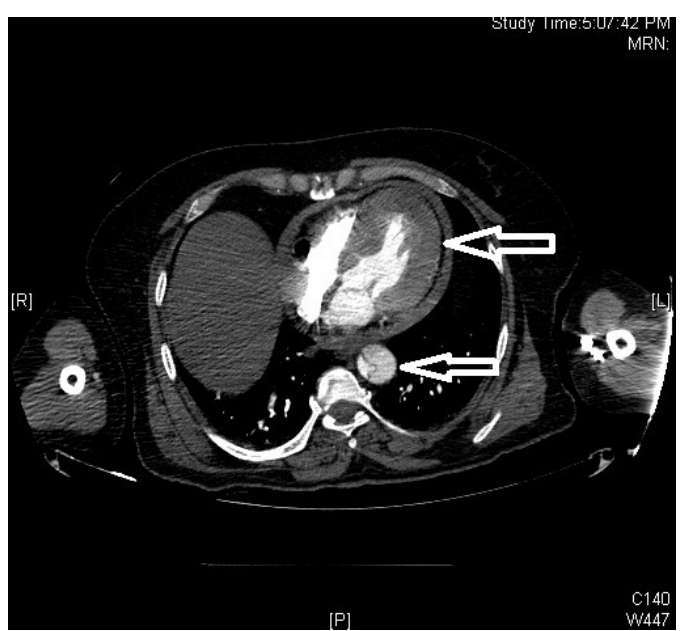

Fig.5: CT aortogram with pericardial effusion and dissection flap in aortic arch. 
Patient underwent Bentall's procedure and was kept in the CTVS Intensive care unit postoperatively. Patient was kept on intravenous antibiotics, anticoagulants and other supportive treatment. Hospital stay was uneventful and patient was discharged in a stable condition after 10 days.

\section{Discussion}

Acute aortic dissection is uncommon but complications including fatality are common. Classic presentations include severe abrupt onset of chest pain. However, clinical manifestations are diverse and the classic symptoms are often absent. We report one such uncommon presentation of aortic dissection which requires a high clinical index of suspicion to aid in diagnosis.

Classification of aortic dissection is based on anatomical location and time from onset of disease. Stanford Type A dissections involves the ascending aorta and Type B dissections occur distal to the left subclavian artery [7]. The 14 day period from the time of onset has been designated as the acute phase, because morbidity and mortality rates are highest and surviving patients typically stabilize during this time. Because presenting clinical features are diverse and serious complications occur rapidly, quick ante-mortem diagnosis is difficult yet imperative [8]. TTE is safe, rapid, and readily available in the emergency department. It should be performed without delay in patients with suspected acute aortic dissection, to evaluate the presence or absence of several important features [9]. An ascending aortic dissection flap may be visible: TTE has a reported sensitivity of $59-83 \%$ and a specificity of $63-93 \%$ for the diagnosis of aortic dissection [10,11]. Computed tomography is the most frequently performed first imaging modality, with near perfect sensitivity and specificity.

\section{Conclusion}

It is important for emergency medicine physicians to have a very high index of suspicion for the prompt diagnosis and treatment of the deadly and relatively rare aortic dissection. Patients can present with atypical signs and symptoms and it is imperative for emergency physicians to recognize and diagnose aortic dissections quickly for prompt appropriate care.

Contributors: AV: manuscript writing, case management; WRS, SJ: manuscript editing, literature search and case management. AV will act as guarantor. All authors approved the final version of the manuscript.

Funding: None; Competing interests: None stated.

\section{References}

1. Acelrno LJ. The History of Cardiology. New York. NY: Parthenon Publishing Group; 1994.

2. DeSanctis RW, Doroghazi RM, Austen WG, Buckley MJ. Aortic dissection. N Engl J Med. 1987;317:10601067.

3. Hsu KC, Tsai SH, Kao HW, Chu SJ, Hsu CW. Acute aortic dissection presenting with acute lower-back pain following sexual intercourse Intern Med Taiwan. 2008;19:418-421.

4. Juang D, Braverman AC, Eagle K. Aortic Dissection. Circulation. 2008;118:e507-e510.

5. Hagan PG, Nienaber CA, Isselbacher EM, Bruckman D, Karavite DJ, Russman PL. The international registry of acute aortic dissection (IRAD): new insights into an old disease. JAMA. 2000;283:897-903.

6. Hirst A, Johns VJ, Krime SJ. Dissecting aneurysm of the aorta: a review of 505 cases. Medicine. 1958;37:217279.

7. Dally PO, Trueblood HW, Stinson EB, Wuerflein RD, Shumway NE. Management of acute aortic dissections. Ann Thorac Surg. 1970;10:237-247.

8. Hirst A, Johns VJ, Krime SJ. Dissecting aneurysm of the aorta: a review of 505 cases. Medicine. 1958;37:217279.

9. Meredith EL, Masani ND. Echocardiography in the emergency assessment of acute aortic syndromes. European J Echocardiog. 2009;10:i31-i39.

10. Miller D. Surgical management of aortic dissections: Indications, perioperative management and long term results. In: Doroghazi RM, Slater EE, eds. Aortic Dissection. New York: McGraw-Hill; 1983: pp.193-243.

11. Appelbaum A, Karp R, Kirklin J. Ascending vs descending aortic dissections. Ann Surg. 1976;183:296300 . 